\title{
Letter: response to article "Is there disadvantage to radical lymph node dissection in colon cancer?"
}

\author{
Sung Uk Bae $\cdot$ Avanish P. Saklani
}

Accepted: 8 May 2013 / Published online: 26 May 2013

(C) Springer-Verlag Berlin Heidelberg 2013

\section{Dear Editor:}

International Journal of Colorectal Diseases

Sir,

We read with interest the article by Weber et al. [1] with update on results of complete mesocolic excision (CME) 1. While this study, unlike most studies, does not state 5-year overall and disease-free survival, 5-year cancer related survival (probably higher than overall survival) in stage 3 is quite remarkable. It seems complete mesocolic excision leads to improved cancer-related survival without any effect on distant metastasis, i.e., improved local control. In this study, chemotherapy seems to have little impact on survival in stage 3 cancers; does this imply good surgery eliminates the need for chemotherapy?

Another thing which seems surprising is that despite radical resections, there were no chyle leaks. In Korea at severance hospital, after D3 resections for right colon, incidence of chyle leaks was $3 \%$ after laparoscopic reactions and $12 \%$ after open reactions (unpublished). Similar high rates of chyle leaks have been reported by Sun et al. [2] $13.3 \%$ after right resections vs. $4.4 \%$ left colon resections. We would be interested about techniques to avoid this complication.

Another concern would be the incidence of superior mesenteric vein injury, which can turn fatal in inexperienced

hands. Like Erlangen, CME is already established in Korea and Japan. However, in the west, unless there is grade 1 evidence from randomised controlled trials regarding complete mesocolic excision, justifying serious complications of radical resection may be labelled adventurous and indefensible.

Many thanks

Yours sincerely,

Dr Sung Uk Bae

Mr A Saklani

\section{References}

1. Weber K, Merkel S, Perrakis A, Hohenberger W (2013) Is there a disadvantage to radical lymph node dissection in colon cancer? International journal of colorectal disease 28(2):217226

2. Sun YW, Chi P, Lin HM, Lu XR, Huang Y, Xu ZB et al (2012) Risk factors of postoperative chyle leak following complete mesocolic excision for colon cancer. Chinese journal of gastrointestinal surgery 15(4):328-331

S. U. Bae $\cdot$ A. P. Saklani

Division of Colorectal Surgery, Department of Surgery, Severance

Hospital, Yonsei University College of Medicine, Seoul,

South Korea

\section{A. P. Saklani $(\bowtie)$}

International Fellow Robotic and Minimal Invasive Surgery, Section of Colon and Rectal Surgery, Department of Surgery, Yonsei University College of Medicine, Seoul, South Korea

e-mail: asaklani@hotmail.com 